\title{
El arte de pintar con plumas. Resurgimiento de la técnica del mosaico en plumaria en Michoacán
}

The Art of Painting with Feathers: The Resurgence of the Mosaic Technique in Featherwork in Michoacan

\author{
Herlinda Ruiz Martínez \\ Programa de doctorado en Historia \\ Universidad Nacional Autónoma de México \\ linruma@yahoo.com.mx
}

Cómo citar este artículo: : Herlinda Ruiz Martínez, "El arte de pintar con plumas. Resurgimiento de la técnica del mosaico en plumaria en Michoacán", en Legajos. Boletín del Archivo General de la Nación, núm. 15 (eneroabril 2018), pp. 83-101.

\section{Resumen}

En las épocas prehispánica y virreinal, el arte plumaria sobresalió gracias a los artesanos michoacanos. Desde finales del virreinato hasta las primeras décadas del siglo xx hubo un periodo de decadencia en la plumaria, misma que resurgió en la segunda mitad de la centuria. En la actualidad el oficio de la plumería es realizado por pocas personas en el país, al considerarse como un arte casi perdido. El siguiente artículo tiene por objetivo central estudiar el resurgimiento, promoción y difusión de la técnica de mosaico para el arte plumaria en Michoacán.

Palabras clave: Arte plumaria, técnica de mosaico, plumas, aves, resurgimiento

\section{Abstract}

In the pre-Hispanic and colonial eras, artisans in Michoacán maintained outstanding traditions of featherwork. During the late colonial period, the art form fell into a long period of decline that lasted until the early decades of the twentieth century, after which its prominence began to rise. Currently, few people in Mexico practice featherwork and the art is all but lost. This article studies the resurgence, promotion, and dissemination of the mosaic technique in featherwork in Michoacan.

Keywords: featherwork, mosaic technique, feathers, birds, resurgence 


\section{Introducción}

Los hombres, en distintas culturas y etapas de la historia, han otorgado fines utilitarios a varios elementos que se encuentran a su alrededor. Uno de ellos es el plumaje de las aves, mismo que ha servido para satisfacer, desde necesidades cotidianas hasta las relacionadas con aspectos conceptuales y simbólicos. ${ }^{1}$ Ximena González comparte dicha opinión y añade que en la actualidad algunos grupos sudamericanos usan las plumas con fines rituales, para señalar su estatus en la sociedad e inclusive como manifestaciones folclóricas. $^{2}$

Por lo anterior, la pluma no solamente forma parte de la vida en varias civilizaciones sino que también se encuentra plasmada en el arte, conocida como plumario o plumaria, trabajada desde tiempos antiguos en algunos pueblos de Asia, África, América e islas del Océano Pacífico, cuyos artesanos han realizado obras con técnicas y aplicaciones variadas, según la región y la época, además de otorgar diferentes significados a la pluma, de acuerdo con su cosmovisión y sus costumbres. ${ }^{3}$ Por ejemplo, durante el Periodo Prehispánico, en la región que ocupó Mesoamérica, tres fueron las técnicas manejadas en plumaria: anudado, con el que se elaboraron penachos, mosqueadores, coronas y abanicos; textil, que derivó en la confección de huipiles, ceñidores, mantas y capas adornadas con plumas pequeñas, y mosaico, representado en escudos de guerra, banderas y discos.

Por otra parte, la plumería trabajada con la técnica de mosaico, tema que atañe a este escrito, en palabras de la maestra e impulsora de la plumaria en Michoacán, Yolanda Sereno,

[...] es el oficio de realizar reproducciones de imágenes de diseños prehispánicos e ideográficos, religiosos del

\footnotetext{
${ }^{1}$ Navarijo, "Plumas...tocados", p. 177.

2 González, "Arte plumario", pp. 47-48.

${ }^{3}$ González, "Arte plumario", p. 48.
} 
culto católico y contemporáneos, con fragmentos de las plumas multicolores de las aves del trópico. Los trabajos son producto de una labor minuciosa y delicada, siendo únicos e irrepetibles por estar hechos con fragmentos de las plumas de las aves. ${ }^{4}$

Si bien se trata de un tema poco abordado, hay investigaciones que coadyuvan al conocimiento de la plumaria, como dan cuenta los estudios de Lourdes Navarijo, María Olvido Moreno, Alfredo Morales, Santiago Muñoz, Laura Filloy y Melanie Korn, quienes han trabajado el caso de México, en tanto que para la región sudamericana existen los textos de Ximena González, Friederike Berlekamp y Christine Giuntini. Varios de los autores citados se abocan a estudios en torno a alguna pieza en particular, lo que deriva en que detallen aspectos técnicos y de conservación, si bien otras indagatorias abordan la plumaria desde enfoques como el biológico y el antropológico, por lo que ofrecen nuevas perspectivas sobre el arte aquí presentado. Pero ahondan más en el estudio Teresa Castelló, Yolanda Sereno y Armando Escobar, quienes exponen el devenir de la plumaria michoacana.

\section{Desarrollo histórico del arte plumaria en Michoacán}

Entre los pueblos precolombinos americanos, la plumaria desempeñó un papel notable, donde el plumaje de las aves, especialmente en las civilizaciones inca y mesoamericanas, resultaba de suma importancia en la vida de quienes las trabajaban, en tanto que quienes las portaban eran asociados con deidades, riqueza, belleza y fertilidad, al considerarse como "la sombra de los

\footnotetext{
${ }^{4}$ Sereno, conversación. Por su parte, Santiago Muñoz define dicho arte simplemente como la "elaboración de objetos por medio de las plumas". Muñoz, "El arte plumario", p. 121.
} 
dioses". ${ }^{5}$ Si bien se presume que los toltecas implementaron la plumaria, las fuentes documentales coinciden en que los grandes maestros en dicho arte fueron mexicas y purépechas, cuyos artesanos alcanzaron un nivel de especialización tan alto que gozaron de privilegios, admiración y respeto de la sociedad.

Con respecto a los habitantes del Valle de México, los objetos elaborados por los artesanos de la pluma "servían para exaltar la jerarquía de dioses, reyes, señores, sacerdotes y soldados". En códices, murales vasijas y esculturas se encuentran plasmados dioses o personajes ricamente ataviados con ostentosos penachos o tocados, portando escudos recubiertos de plumas o bien, tributándolas. Los plumajeros que trabajaban en el palacio tenían

...un sitio privilegiado para la obtención de las plumas necesarias en su oficio: la célebre Casa de las Aves de Moctezuma, suerte de zoológico que formaba parte del complejo palaciego. [...] las aves en cautiverio no sólo estaban destinadas para la contemplación del rey y su corte, sino que también servían como fuente inagotable de plumas. ${ }^{7}$

A estos personajes se les llamaba tecpan amantecas o "plumarios de la casa real", en tanto que otros eran nombrados calpinzin amantecas y se

${ }^{5}$ Ximena González subraya que entre los incas "reclutaban maestros tejedores de plumas, pillcocamayos, de los distintos puntos del imperio, quienes eran elevados a un estatus especial dentro de su corte". González, "Arte plumario", p. 51. Lourdes Navarijo señala que la pluma se asocia entre su ligereza, pertenencia a todas las aves y el vuelo, las alturas y por consiguiente la comunicación con lo espiritual e inalcanzable y destaca la importancia de los portadores de plumas en la estratificación social de los pueblos mesoamericanos. Navarijo, "Plumas...tocados", pp. 189, 180. Y Ximena González apunta la creencia de que, quienes vestían plumas tomaban la divinidad de los pájaros y adquirían sus cualidades. González, "Arte plumario", p. 47.

${ }^{6}$ Filloy, Solís y Navarijo, "Un excepcional mosaico", p. 85. Incluso las plumas llamativas de las aves tropicales tenían un valor igual o mayor que el oro. Sereno, La magia, p. 10.

${ }^{7}$ Filloy, Solís y Navarijo, "Un excepcional mosaico", p. 96. 
dedicaban a elaborar los trajes para danzas rituales, y los artesanos domésticos, conocidos como callimanteca fabricaban y comerciaban en el tianguis escudos y demás artículos en pluma. ${ }^{8}$

En cuanto a los oficiales de la pluma en la civilización purépecha, eran denominados como uscuarecuri, que significa "maestro de la pluma" y unos más recibían el nombre de uscuarecucha o "artífice de la pluma". La principal fuente documental que brinda información sobre ellos es La Relación de Michoacán, misma que alude al uso dado a las plumas en bastones de mando, penachos, escudos de guerra y banderas. En torno al plumajero se relata lo siguiente:

Había otro llamado usquarecuri, diputado sobre todos los plumajeros que labraban de pluma los atavíos de sus dioses y hacían los plumajes para bailar. Todavía hay estos plumajeros. Éstos tienen por los pueblos muchos papagayos grandes colorados y de otros papagayos para la pluma, y otros les traían pluma de garzas, entre otras maneras de pluma de aves. ${ }^{9}$

La misma obra señala cómo el plumaje acompañaba a los gobernantes incluso en la muerte. ${ }^{10}$

A la llegada de los conquistadores españoles, la importancia de las plumas continuaba vigente, como describió Hernán Cortés, en las Cartas de Relación, al referirse a la calle de caza en tianguis de Tlatelolco: "venden todos los linajes de aves que hay en la tierra, así como gallinas, perdices, codornices, lavancos, dorales, zarcetas, tórtolas, palomas, pajaritos en cañuela, papagayos, búharos, águilas, halcones, gavilanes y cernícalos". ${ }^{11}$ Sin embargo, su valor muy pronto decayó ante el deseo de los militares por los metales preciosos y la consiguiente destrucción de elementos tanto simbólicos como materiales

\footnotetext{
${ }^{8}$ Sereno, La magia, p. 9.

${ }^{9}$ Alcalá, Relación de Michoacán, p. 561.

${ }^{10}$ Alcalá, Relación de Michoacán, pp. 624-625.

${ }^{11}$ Cortés, Cartas, p. 77.
} 
de los pueblos recién conquistados, entre los que encontraban varios objetos en pluma, si bien algunos se salvaron y generaron entre los iberos admiración, al grado de remitir a España piezas como penachos y escudos, no todos llegaron a su destino. ${ }^{12}$

Con el arribo de los evangelizadores, la plumaria recobró fuerza, debido a que los religiosos aprovecharon la habilidad de las manos nativas para dar continuidad a su práctica mediante nuevos usos, al incorporar (como una manera de cristianizar) las plumas al arte sacro, materia prima que desempeñó un papel importante al momento de confeccionar casullas, capas pluviales, mucetas, mitras y cendales para cristos, además de mosaicos o cuadros con imágenes alusivas a la religión católica. Por lo anterior, se dio un proceso de transculturación al fusionarse técnica y elementos prehispánicos con temáticas religiosas provenientes de España. ${ }^{13}$ Sin embargo, Santiago Muñoz señala que "los significados de la pluma se perdieron, para volverse simplemente contendores de los mensajes iconográficos europeos". ${ }^{14}$

$\mathrm{Al}$ mismo tiempo, los frailes promovieron la fundación de escuelas de artes y oficios adjuntas a monasterios, en las cuales incluyeron talleres del arte en pluma. ${ }^{15}$ En la Ciudad de México se instruyó la plumaria en la Escuela de San José de Belén de los Naturales y en el Colegio para Indios Nobles de la Santa Cruz de Tlatelolco. Teresa Castelló señala que "la producción de mosaicos de pluma decayó notablemente en otras regiones de Nueva España, excepto en la ciudad de México donde perduró en el Colegio de Betlemitas hasta que se suprimió éste en 1820". ${ }^{16}$

${ }^{12}$ Como da cuenta el episodio del corsario francés Jean Fleury, quien capturó naves que transportaban riquezas provenientes del territorio recién ocupado, entre las que se encontraban objetos en pluma, de los que se presume varios fueron elaborados en Michoacán. Sereno, La Sombra, p. 12.

${ }^{13}$ Morales, "Un San Jerónimo", p. 215. Muñoz, "El arte plumario”, pp. 130, 145.

${ }^{14}$ Muñoz, "El arte plumario", p. 122.

${ }^{15}$ Morales, "Un San Jerónimo", p. 215.

${ }^{16}$ Castelló, "La plumaria", p. 152. La plumería incursionó, de manera aislada, en conventos como los de Huejotzingo, Cuetzalan y Calpan, en Puebla. 
Por lo que respecta a la plumaria en Michoacán, sobresalieron desde el siglo xvi los plumajeros de los talleres en Pátzcuaro y Tiripetío. En el último poblado mencionado "los frailes agustinos se preocuparon por conservar y perfeccionar las artesanías propias de los purépechas, entre ellas la plumaria". ${ }^{17}$ Por su parte, los agremiados de Pátzcuaro empleaban la materia prima para elaborar mosaicos alusivos a cristos, vírgenes, santos y obispos plasmados en escenografías celestiales, donde la totalidad del cuadro estaba elaborada en pluma. ${ }^{18}$ Para el siglo XVII los plumajeros intercalaron la materia prima con papel de china cubierto de laminillas doradas para destacar los bordes de la vestimenta en las imágenes sacras y durante el siglo xviII las obras de vírgenes y santos llevaron rostros y extremidades pintadas al óleo, de acuerdo con las tendencias artísticas en Europa. ${ }^{19}$ Hacia el ocaso de la centuria decayó el arte plumaria en Michoacán, debido a la migración hacia otros poblados, de los maestros en Tiripetío y Pátzcuaro.

Las fuentes consultadas para este estudio concuerdan al plasmar reacciones procedentes de Europa, mismas que resultaron favorables hacia la plumaria, puesto que quienes apreciaron las obras veían dicho arte (cuya iconografía era en su mayoría sacra) con asombro, curiosidad y admiración al considerarlo como algo novedoso, exótico y desconocido, como señalan algunos autores. ${ }^{20} \mathrm{Y}$ el aprecio por las piezas fue más allá de la admiración, dado que varias de ellas fueron

${ }^{17}$ Castelló, "La plumaria", p. 152.

${ }^{18} 1590$ el oficio de plumajero en Pátzcuaro gozaba de ciertos privilegios. Inclusive el primer obispo de Michoacán, Vasco de Quiroga, gustó y difundió la plumaria con el envío de obras a Europa y el uso personal de mitras y capas de damasco con detalles en pluma, como se enlista en su testamento.

${ }^{19}$ Sereno, La magia, pp. 30, 32.

${ }^{20}$ Filloy, Solís y Navarijo, "Un excepcional mosaico", pp. 85-86. Morales, "Un San Jerónimo", p. 216. Inclusive cronistas como Antonio de Ciudad Real, Joseph de Acosta, Juan de Torquemada, Alonso de la Rea y Matías de Escobar manifestaron su impresión, de manera frecuente y positiva hacia la plumaria michoacana, de la cual consideraban a sus plumajeros, en la técnica del mosaico, como los mejores en Nueva España. 
Imagen 1. "Nuestra Señora de la Salud de Pátzcuaro", siglo XVIII. Procedencia: Museo Etnográfico de Berlín.

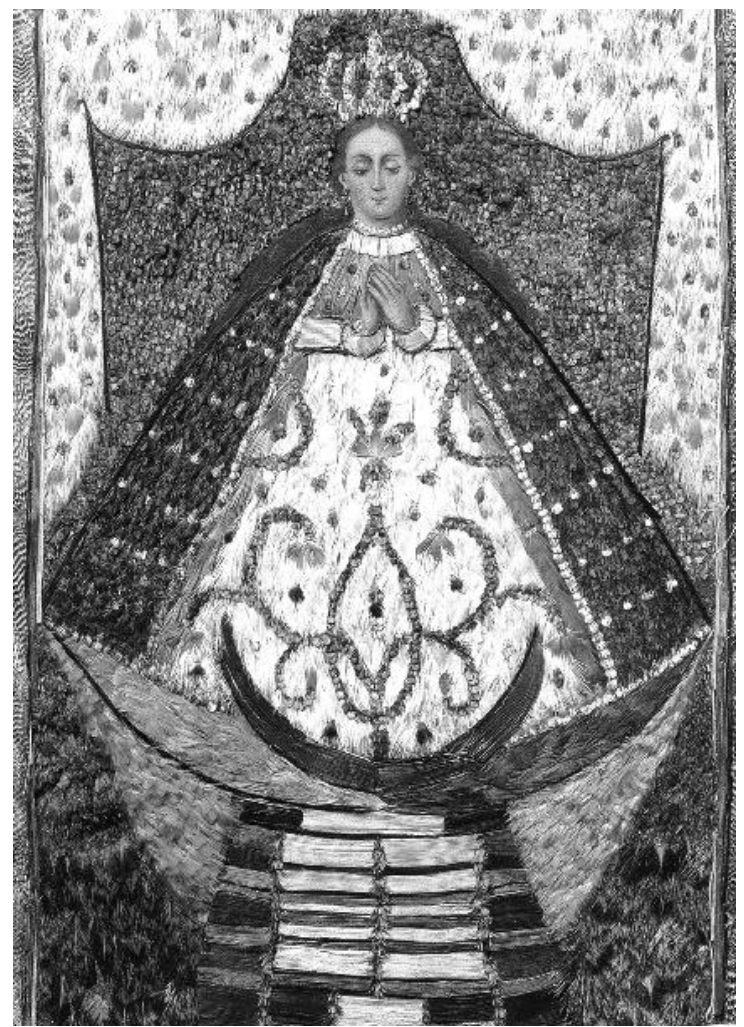

Fuente: Castelló, "La plumaria”, p. 149.

obsequiadas a las altas esferas del poder civil y eclesiástico europeo entre los siglos XVI y XVIII. ${ }^{21}$

Pese a la existencia de estudios que abordan el desarrollo histórico de la plumaria michoacana durante el periodo virreinal, es necesario señalar que los siglos XIx y xx presentan lagunas historiográficas, y únicamente los textos de Armando Escobar y Yolanda Sereno ofrecen algunas pistas, mismas que serán retomadas a continuación.

${ }^{21}$ Morales, "Un San Jerónimo", pp. 216-217. 


\section{Resurgimiento y pervivencia de la plumaria michoacana}

A mediados del siglo xx, Gabriel Olay Olay, originario de la ciudad de México, cambió su domicilio al pueblo michoacano de Tlalpujahua donde se dedicó, de manera formal, a la técnica de mosaico, misma que instruyó en su familia. "Olay procedía de una familia de antiguos plumajeros de la capital que a principios del siglo xx se había dedicado a la producción masiva de tarjetas postales recreadas con reproducciones de aves con plumas pintadas artificialmente". ${ }^{22}$ Heredó los conocimientos de plumaria gracias a su padre, quien a su vez fue instruido por un indio de apellido López, descendiente de amantecas. Gracias al trabajo del maestro Olay la plumería renació, aunque el mayor resurgimiento y difusión del "arte de pintar con plumas" se desarrollaría en el ocaso de la centuria, con talleres de plumaria e investigaciones sobre la materia.

En 1993 fue publicado el libro El arte plumaria en México, coordinado por Teresa Castelló, con el auspicio del Fomento Cultural Banamex. El texto fue pieza clave para que la periodista e interesada en el arte en Michoacán, Yolanda Sereno, buscara abrir un taller de plumaria con el fin de investigar más a fondo sobre el tema, producir obras bajo la técnica del mosaico y difundirlas. Varios meses después, durante la gestión del rector de la Universidad de San Nicolás de Hidalgo, el licenciado Daniel Trujillo Mesina, a través de la Secretaría de Difusión Cultural, encabezada por Armando Mauricio Escobar Olmedo, se brindó el apoyo para abrir un Taller Experimental de Plumaria en el ex convento de Tiripetío, lugar donde se había impartido el arte en pluma siglos atrás.

De esta manera, se fundó un curso experimental de plumaria, que tuvo como profesora a Yolanda Sereno, quien actualmente continúa con su taller, de manera constante e ininterrumpida, por lo cual se cumplieron los objetivos planteados en un inicio y con ello no solo

${ }^{22}$ Sereno, La magia, p. 38. 
resurgió, sino que también comenzó a difundirse el arte plumaria entre personas (en su mayoría mujeres) interesadas en aprender, principalmente la técnica de mosaico, con el objetivo de revivir la plumaria, preservando su técnica y su esencia, ${ }^{23}$ pese a que las primeras obras ejecutadas en mosaico por los aprendices eran muy sencillas.

Ocho años después de la fundación del taller, ante la demanda de abrir una escuela de plumaria en la ciudad de Morelia, se trasladó su sede a la capital, donde hasta la fecha se mantiene en funcionamiento, acogiendo entre sus alumnos a personas de Michoacán y de otros estados del país. Del taller fundado por Yolanda Sereno, es importante destacar que algunas egresadas abrieron sus propios cursos de plumaria al interior del estado de Michoacán y en otros puntos de la República.

Por otra parte, y con respecto a algunas cuestiones técnicas de la plumaria actual, es pertinente indicar que la mayoría de las obras son cuadros elaborados, total o parcialmente con pluma natural, teñida y en diferentes soportes como cartones, maderas y papeles gruesos; también se considera como parte de la plumaria el arte-objeto con cajas, cruces de ornato, barro, joyería, máscaras e inclusive cascarones de huevo de avestruz que se revisten con plumas (véase imagen 2).

Imagen 2. "Máscara funeraria prehispánica". Yolanda Sereno Ayala, 2010.

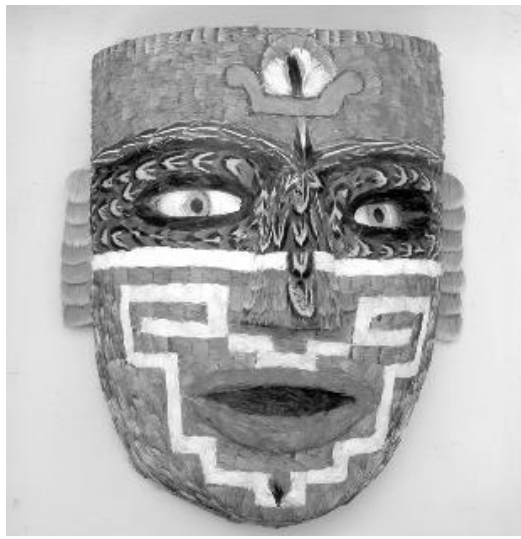

Fuente: Imagen tomada por Yolanda Sereno Ayala.

${ }^{23}$ Sereno, La magia, p. 2. 
Es importante presentar, a grandes rasgos, el procedimiento seguido por los plumajeros, para comprender mejor la manera en que trabajan. Así, el proceso inicia con la obtención de la materia prima a través de la "pelecha" o muda de plumas o bien, del despojo de plumaje en los cuerpos de los pájaros fallecidos por causas naturales. La materia prima se lava, se desinfecta y se separa. El siguiente paso es elegir un diseño y dibujarlo sobre la superficie en la cual se trabajará, untar sobre él un pegamento (cera de Campeche) y, con ayuda de unas pinzas finas, colocar pluma por pluma, previamente recortada con tijeras, por lo que se debe cuidar el uso de los colores, tamaños y formas de la pluma, que resultan de suma importancia para matizar y dar cuerpo a la obra, puesto que cada plumajero imprime su sello personal, de acuerdo con su experiencia y habilidades aprendidas con la práctica, mismas que se ajustan a las características de la pieza, cuyo tiempo de elaboración es variado (días, semanas, meses), al tratarse de una labor ardua que requiere de paciencia, creatividad, concentración y amor a un arte surgido en tiempos prehispánicos (véase imagen 3).

Imagen 3. Plumajera trabajando, 2017.

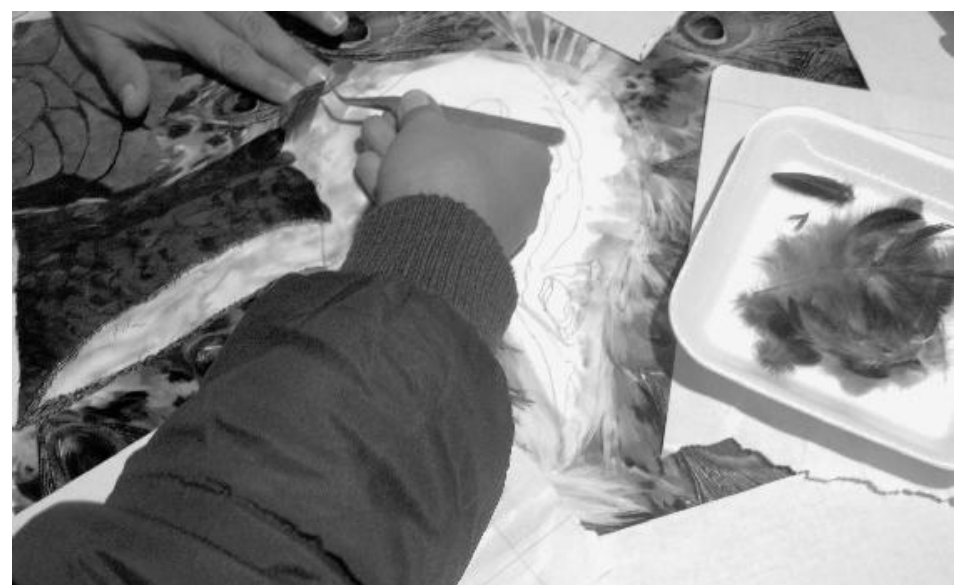

Fuente: Imagen tomada por Herlinda Ruiz Martínez.

Dentro de los talleres, al constituir la pluma la materia prima para el artista, se habla a los alumnos acerca de las principales aves en México y Michoacán, se realizan recorridos didácticos por aviaros 
para apreciar de cerca a los ejemplares, la composición del plumaje, tipos de pluma y se enfatiza en la importancia de proteger a las aves, por lo que los plumajeros actuales, al igual que los uscuarecuchas y amantecas, abogan por la preservación del ecosistema, pero sin olvidar el arte ancestral. Asimismo, se pretende difundir la importancia históricocultural de la plumaria, por medio de observación directa de obras en recintos que resguardan piezas elaboradas durante el Virreinato.

Si bien el arte es colorido y digno de admirar, sus artesanos enfrentan al reto de conseguir las plumas naturales de las aves, puesto que las teñidas artificialmente pierden su color con el paso del tiempo. Así, Betzabé Cárdenas refiere que "conseguir plumas es algo que debemos valorar, puesto que es difícil obtener la materia prima de un ser que tiene vida, lo cual nos hace tener un mayor respeto a la naturaleza al hacer uso de la pluma". ${ }^{24}$

Otra limitante a la que se enfrentan es la falta de apoyo para la difusión de eventos como exposiciones al interior del país y reconocen no contar con ayuda por parte de algunas instituciones con respecto a la investigación en torno, por ejemplo, a la experimentación de materiales y pegamentos, así como para la comercialización, al interior del país, de los objetos elaborados, "puesto que las autoridades le restan importancia a la cultura en general". ${ }^{25}$ Sumando a lo anterior, es bastante reducido el número de oficiales de la pluma en el país que aportan al rescate, con trabajos de calidad, de esta herencia cultural en Tabasco, Puebla, Hidalgo, Nuevo León, Veracruz y la Ciudad de México, aunque es en Michoacán donde se encuentra el mayor número de plumajeros cuyas piezas de calidad han merecido elogios de especialistas en la materia, como Teresa Castelló. ${ }^{26}$

${ }^{24}$ Cárdenas, conversación.

${ }^{25}$ Sereno, conversación.

${ }^{26}$ Ejemplo de ello es la familia Olay, cuyo patriarca, el maestro Gabriel Olay Olay, dejó su enseñanza a su familia, la cual ha continuado con la labor en pluma. Olay Barrientos, "Oficial de pluma", pp. 67-116. Otro caso, aunque menos conocido, es el de un plumajero llamado Aurelio Franco, quien realizó obras de plumaria en Veracruz. Lemus Olvera, "El arte plumario", pp. 58-62. 
Imagen 4. "Convento de Tiripetío". Dolores Ortiz, 2000.

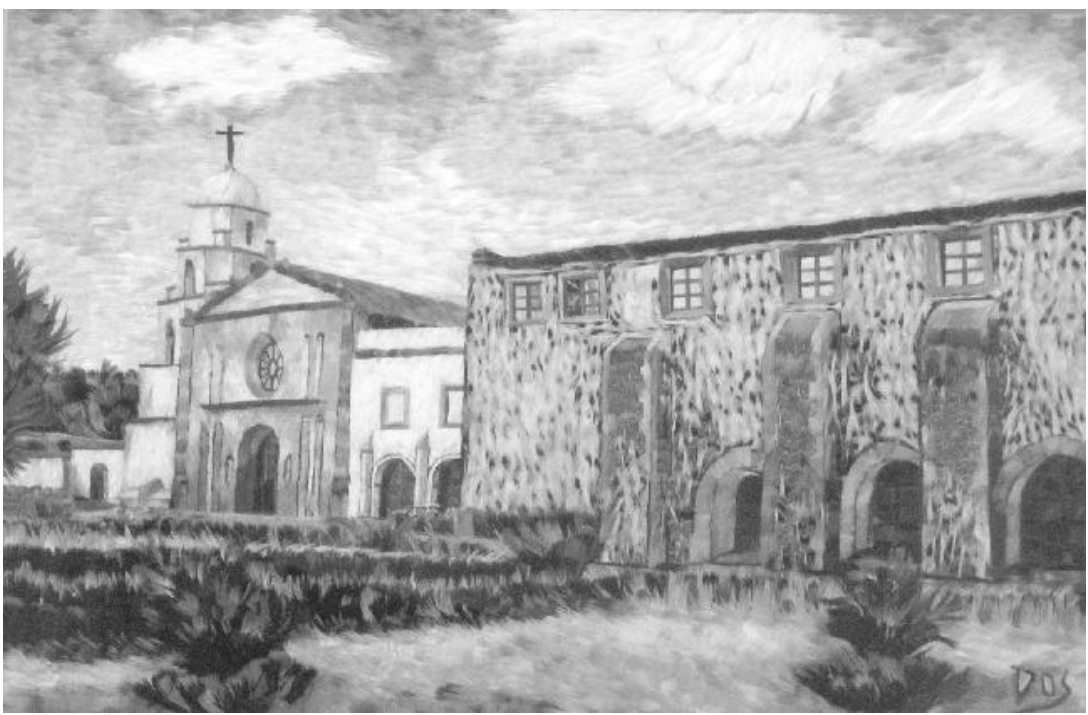

Fuente: Imagen tomada por Yolanda Sereno Ayala.

Imagen 5. "Tarahumara". Sbaidy Melchor Herrejón, 2017.

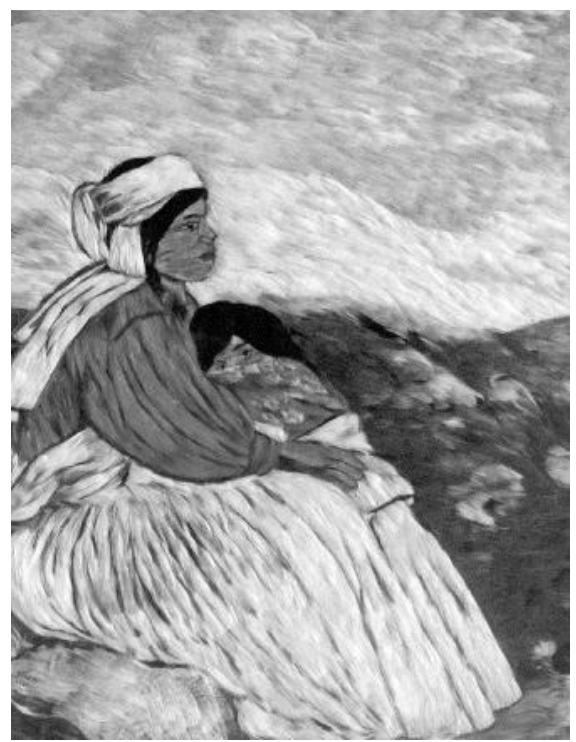

Fuente: Imagen tomada por Yolanda Sereno Ayala. Pieza ganadora del 3er lugar en el Gran Premio de Arte Popular 2018. 
Por su parte, Sereno señala que "en Michoacán se empieza a reconocer esta manifestación artística", ${ }^{27}$ lo cual representa una importante tarea que los plumajeros deben realizar como medio de rescate y difusión del arte que desarrollan, buscando nuevos caminos en el diseño, por ejemplo, el incluir el mosaico en objetos utilitarios para dar a conocer su valor a nivel nacional e internacional y lograr que la plumaria llegue a ser parte del patrimonio cultural de Michoacán. Con ello, la pluma adquiere importancia artística y un sentido utilitario al brindar, como se mencionó anteriormente, "nueva vida al plumaje de las aves, lo cual deriva en un enriquecimiento colectivo, motivacional e inclusive terapéutico para quienes pertenecemos al taller de plumaria". ${ }^{28}$ De esta manera, se alcanza el objetivo de rescatar la plumaria en Michoacán al "legitimar su arraigo entre los purépechas, además de recordar su importancia ancestral y cultural, que pervive hasta nuestros días". ${ }^{29}$

\section{Consideraciones finales}

El uso y aprovechamiento del plumaje de las aves a manos de civilizaciones mesoamericanas como la mexica y la purépecha derivó en la plumaria, misma que adquirió gran importancia y se posicionó como el arte más importante y apreciado durante el periodo prehispánico. Con la llegada de los evangelizadores la plumería sufrió importantes cambios, de acuerdo con el proceso de transculturación, al fusionarse técnicas prehispánicas y temáticas religiosas que propiciaron la apertura de escuelas y talleres, cuyos agremiados michoacanos sobresalieron con obras que generaron admiración en Nueva España y Europa. Pese a un periodo de declive entre los siglos xix y primeras décadas del siglo $\mathrm{xx}$, debido a guerras, inestabilidad social y dificultades derivadas de la plumaria dicho arte, casi extinto, resurgió con los trabajos

${ }^{27}$ Israel Santacruz, "Grupo Quetzal revive", La Voz de Michoacán, Morelia, 9 de septiembre de 2007, p. 8G.

${ }^{28}$ Cárdenas, conversación.

${ }^{29}$ Aguilera, conversación. 
de Gabriel Olay, sumado a posteriores investigaciones especializadas en la plumería, la apertura del taller en Tiripetío y la difusión del arte en pluma a través de concursos de artesanías, donde la plumaria cuenta con una categoría especial dentro de las ramas de producción artesanal y varios plumajeros han sido premiados; además de exposiciones y comercialización de piezas.

Con el resurgimiento del arte plumaria, no solo se rescató un arte que corría el peligro de extinguirse, sino que también se retomaron los procedimientos de elaboración de obras en mosaico, donde convergen la tradición ancestral y la moderna a través de la elaboración de cuadros o arte-objeto, con una diversidad de temáticas que se alejan de la iconografía religiosa predominante durante los periodos Prehispánico y Virreinal, permitiendo que esta técnica añeja perviva en el arte popular mexicano. ${ }^{30}$ Es por ello que los plumajeros actuales otorgan al plumaje de las aves un significado artístico y nueva vida buscando, como asevera Betzabé Cárdenas, "rescatar y dar un nuevo valor a la pluma, mismo que debemos preservar histórica y artísticamente". ${ }^{31}$

Sin embargo, la tarea no resulta sencilla, puesto que los plumajeros deben enfrentar retos como la escasez de algunas plumas naturales requeridas para trabajar, el poco valor que se da a un arte donde los michoacanos han sobresalido y la falta de apoyo por parte de algunas autoridades. Pese a que el panorama de la plumaria se vislumbra complicado, al mismo tiempo es esperanzador, debido a que dicho arte continúa vigente y gana paulatinamente nuevos plumajeros, así como la admiración y el aprecio de la gente.

\footnotetext{
${ }^{30}$ González, "Arte plumario", p. 52.

${ }^{31}$ Cárdenas, conversación.
} 
Imagen 6. "La excomunión de Hidalgo". Laura Ruiz Martínez, 2010.

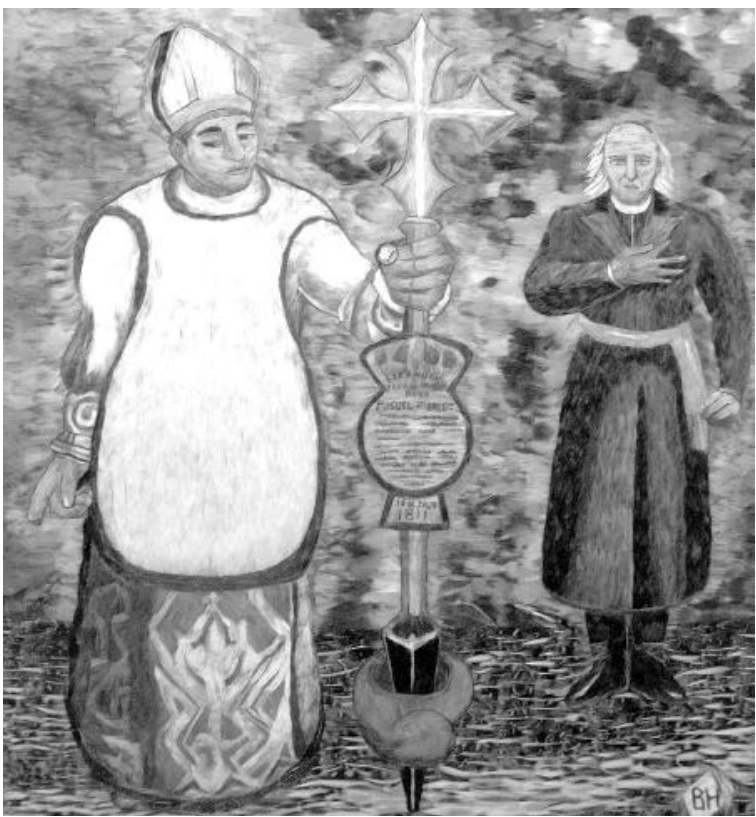

Fuente: Imagen tomada por Yolanda Sereno Ayala.

Imagen 7. "La danza del pescado". Ma. Del Refugio Vega Esquivel, 2017.

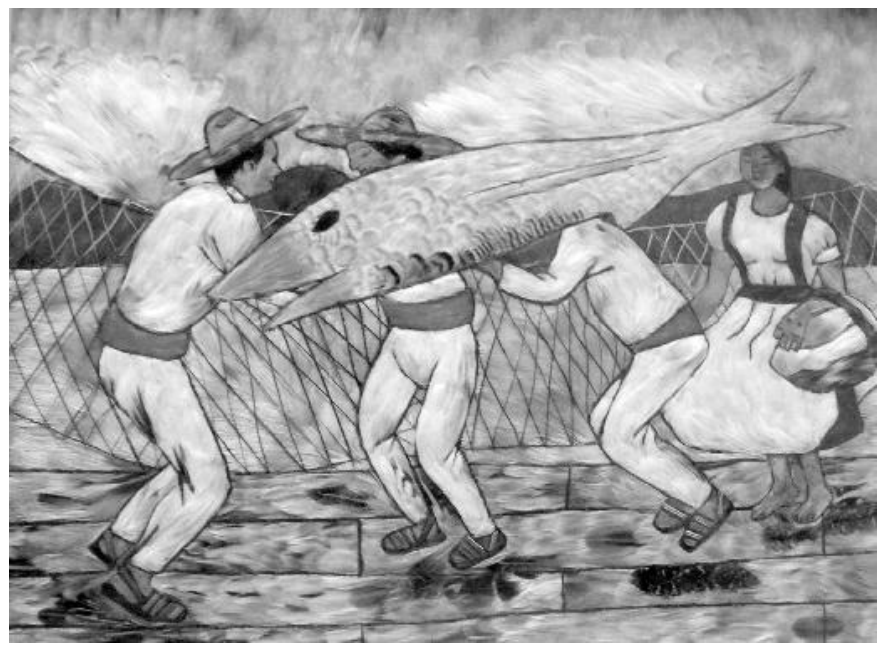

Fuente: Imagen tomada por Yolanda Sereno Ayala. 
Herlinda Ruiz Martínez

El arte de pintar con plumas...

Imagen 8. "Popocatépetl”. Irma Sánchez, 2012.

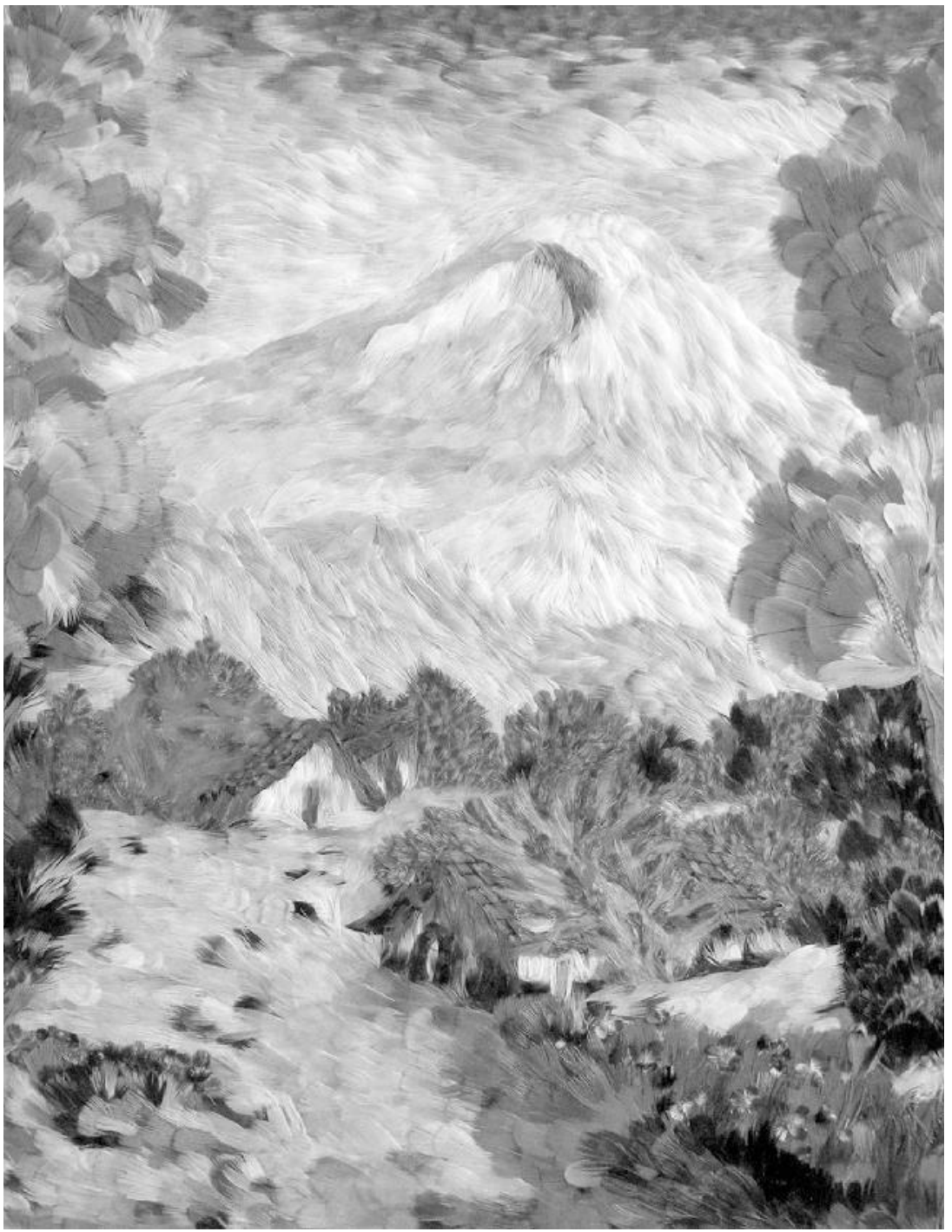

Fuente: Imagen tomada por Yolanda Sereno Ayala. 


\section{Fuentes}

\section{Bibliografía}

Alcalá, Fray Jerónimo de, Relación de las ceremonias y rictos y población y gobernación de los indios de la Provincia de Mechuacán, coord. de edición y estudios Moisés Franco Mendoza, Zamora, El Colegio de Michoacán, Gobierno del estado de Michoacán, 2000.

Castelló Yturbide, Teresa (coord.), "La plumaria en la tradición indígena", en Castelló Yturbide, Teresa (coord.), El arte plumaria en México, México, Fomento Cultural Banamex A.C., 1993, pp. 143-217.

Cortés, Hernán, Cartas de Relación, México, Porrúa, 24ª ed., 2013.

Escobar Olmedo, Armando Mauricio, "Plumaria Michoacana", en Verónica Oikión Solano (coord.), Manos Michoacanas, Zamora, El Colegio de Michoacán, Gobierno del estado de Michoacán, umsnh, IIH, 1997, pp. 161-175.

Navarijo Ornelas, María de Lourdes, "Plumas...tocados: una vieja historia de identidades perdidas", en Beatriz de la Fuente (coord.), La pintura mural prehispánica en México, vol. 2, t. 1, Área Maya. Bonampak, México, unam, IIE, 2001, pp. 177-191.

Sereno Ayala, Yolanda, "La magia de las plumas", en La Voz de Michoacán, Morelia, 2013.

Sereno Ayala, Yolanda, "La sombra de los Dioses. Arte plumario", en La Voz de Michoacán, Morelia, 2005.

\section{Hemerografía}

Filloy Nadal, Laura, Solís Olguín, Felipe y Navarijo, Lourdes, "Un excepcional mosaico de plumaria azteca: el Tapacáliz del Museo Nacional de Antropología”, en Estudios de Cultura Náhuatl, vol. 38, 2007, pp. 85-100. 
González, Ximena, "Arte plumario en América”, en, Datatèxtil, núm. 23, 2010, pp. 46-55.

Lemus Olvera, Rafael, "El arte plumario o las caricias de las formas", en México Desconocido, núm. 172, año xiv, junio de 1991, pp. 58-62.

Morales, Alfredo J., "Un San Jerónimo de arte plumaria en el convento de San José de Sevilla”, en Laboratorio de Arte, núm. 24, 2012, pp. 215-223.

Muñoz, Santiago, "El 'Arte Plumario' y sus múltiples dimensiones de significación. La Misa de San Gregorio, Virreinato de la Nueva España, 1539", en Historia Crítica, núm. 31, enero-junio de 2006, pp. 121-149.

Olay Barrientos, María de los Ángeles, "Oficial de pluma. Recuerdo de una tradición alada", en Tzintzun. Revista de Estudios Históricos, núm. 33, enero-junio, 2001, pp. 67-116.

Santacruz, Israel, "Grupo Quetzal revive la herencia plumaria", en $L a$ Voz de Michoacán, 9 de septiembre de 2007, Regional, p. 8G.

\section{Conversaciones}

Betzabé Cárdenas González (plumajera), en conversación con la autora, 10 de marzo de 2018.

Daniel Trujillo Mesina (rector de la Universidad Michoacana de San Nicolás de Hidalgo durante el periodo 1990-1994), en conversación con la autora, 28 de febrero de 2018.

María Inés Aguilera Mandujano (plumajera), en conversación con la autora, 10 de marzo de 2018.

Yolanda Sereno Ayala (periodista y maestra de arte plumaria), en conversación con la autora, 14 de diciembre de 2017. 